\title{
Shelter competition between the invasive western tubenose goby and the native stone loach is mediated by sex
}

\author{
Dagmara BŁOŃSKA, ${ }^{1}$ Jarosław KOBAK, ${ }^{2}$ Joanna GRABOWSKA ${ }^{1 *}$ \\ ${ }^{1}$ Department of Ecology and Vertebrate Zoology, Faculty of Biology and Environmental Protection, University of Lodz, ul. Banacha \\ 12/16, 90-237 Łódź; ${ }^{2}$ Department of Invertebrate Zoology, Faculty of Biology and Environmental Protection, Nicolaus Copernicus \\ University, Lwowska 1, 87-100 Toruń, Poland \\ *Corresponding author: joko@biol.uni.lodz.pl
}

\begin{abstract}
Shelter, regarded as a protection against predators and/or nesting site, constitutes one of the basic resources for which organisms compete in the wild. Ponto-Caspian gobies are a good example of a territorial species, which can have negative impact on native species with similar biology due to competitive interactions. Thus, the aim of the present study was to investigate the potential impact of the invasive Ponto-Caspian western tubenose goby Proterorhinus semilunaris on the native stone loach Barbatula barbatula through shelter competition. We used male and female gobies in their reproductive season to test whether they would be more aggressive towards native stone loach, accounting for different light conditions in a limited shelter competition scenario. The results of our study showed that both tested species occupied the shelter mostly during the daylight. Only male goby reduced the shelter occupancy of stone loach despite the fact that interspecific aggressive acts were very rare. It was associated with the nest guarding by male gobies, considering that the study was conducted during their reproductive season. Based on our results, it is possible that, under natural conditions, male tubenose goby would force stone loach to stay away from the shelter, especially in late spring and early summer, when gobies are in reproductive state. This might affect stone loach populations by devoiding them of optimum sites and increasing their exposure to predators.
\end{abstract}

Key words: Alien species impact; Proterorhinus semilunaris; Barbatula barbatula.

Received: July 2016. Accepted: November 2016.

\section{INTRODUCTION}

Over the last decades, the number of alien species invading Europe causing dramatic ecological changes (Rahel, 2002; Keller et al., 2011). Freshwater ecosystems are particularly vulnerable to invasions and indeed the freshwater fauna undergo gradual replacement of native species by non-indigenous organisms, increasing regional homogenisation (Rahel, 2002; Villéger et al., 2011). In many cases alien species negatively affect natives and may impact the native biodiversity and ecosystem functioning. Among aquatic animals, fishes are at the same time the taxon with the higher proportion of introduced species and with the higher number of species threatened by biological invasions (Gozlan et al., 2010).

There are several studies from Europe and the North American Laurentian Great Lakes which regard PontoCaspian gobies as very successful invaders (Ricciardi and MacIsaac, 2000; Ricciardi, 2001; Copp et al., 2005; Roche et al., 2013). It has been shown that these benthic fish may have an adverse impact on native species sharing or overlapping their ecological niche and especially through competitive interactions (Dubs and Corkum, 1996; Janssen and Jude, 2001; Van Kessel et al., 2011; Kakareko et al., 2013; Jermacz et al., 2015; Grabowska et al., 2016). In the Vistula River catchment, four species of Ponto-Caspian gobies had been recorded up to now (Grabowska et al., 2008, 2010; Semenchenko et al., 2011) and among them the western tubenose goby Proterorhinus semilunaris expands its range most rapidly, being currently the most abundant goby species in the Vistula River catchment (own unpublished observations). The European bullhead and stone loach Barbatula barbatula are among native benthic fish species co-occurring with non-native gobies (Penczak et al., 2010; Jażdżewski et al., 2012). Both species utilize shelters (Van Kessel et al., 2011), and therefore they are commonly found among stones offering many hideouts. At high density of both native fish and introduced Ponto-Caspian gobies, shelters can be temporarily or permanently limited.

For the stone loach, shelters serve exclusively as refuges and protection against predators (MacKenzie and Greenberg, 1998), whereas solitary and territorial bullhead use them also as nests, which are aggressively defended by males during the reproductive season (Mills and Mann, 1983). Shelters, like crevices under and among stones, are also important for gobies, which display a similar behaviour to that of the bullhead, with territorial males guarding their nests (Miller, 1984; Grabowska et al., 2016). The influence of the spawning season on the in- 
tensity of interactions between gobies and European bullhead was shown experimentally by Grabowska et al. (2016) and Błońska et al. (2016), but the interactions with stone loach are fairly less studied. Moreover, the affinity for a shelter and its seasonal changes differ between goby species. In spring, when spawning takes place, tubenose, monkey and racer gobies were interested in seizing shelters, while after the reproductive period (autumn) only tubenose goby remained associated with shelters, whereas the other species considerably decreased their shelter occupancy (Błońska et al., 2016; Grabowska et al., 2016). This indicates that under experimental conditions the western tubenose goby has the highest affinity for a shelter throughout the year among the Ponto-Caspian gobies tested.

Until now, the interactions between stone loach and invasive gobies have been a subject of only one study, which did not show any negative influence of PontoCaspian gobies (round, bighead, tubenose and monkey goby) on the shelter use by the stone loach (Van Kessel et al. 2011). However, in this study two potentially important factors for competition intensity were not taken into consideration: the experiments were conducted only after the spawning season of gobies, when their territorial behaviours are less intense, and their sex was not determined. Similarly, in other studies on competitive interactions between gobies and native species, the sex of the tested gobies was either not determined (Dubs and Corkum, 1996; Kakareko et al., 2013; Jermacz et al., 2015) or only males were used (Balshine et al., 2005; Błońska et al., 2016; Grabowska et al., 2016). Thus, the objective of the present study was to investigate experimentally the influence of the Ponto-Caspian western tubenose goby on shelter occupation by the stone loach taking into account the sex of goby, during the goby reproductive season (i.e., in late spring). We hypothesized that the stone loach, considered as rather evasive (Prenda et al., 1997; Fischer, 2000) and exploiting shelters as refuges only, would be outcompeted by tubenose goby males, while the influence of goby females would be much weaker, if any. Moreover, the shelter occupancy by both species, regardless of their sex, would depend on light conditions (daylight/night) and/or their diel activity patterns.

\section{METHODS}

\section{Sampling}

Specimens of the western tubenose goby were collected in May 2015 from the lower section of the Vistula River (in the backwater of the Włocławski Reservoir), near the city of Płock (19³1'E; 52 36'N). Stone loaches were collected in June 2015 from the Mroga River (trib- utary of the Bzura River, the Vistula River catchment, $\left.19^{\circ} 50^{\prime} \mathrm{E} ; 51^{\circ} 48^{\prime} \mathrm{N}\right)$, where no goby species have been recorded and therefore the tested stone loach individuals did not have any experience with this alien species before the experiment. Adult fish were obtained under the permission of particular water tenants (L.dz. 295/ZiOW/2015 for gobies, L.dz 13/15 for stone loaches). Due to the protected status of the stone loach in Poland also a permission of Regional Directorate for Environmental Protection was necessary (no. WPN-II.6401.52.2015.KW2). After the experiments, according to applicable law, all stone loaches were released in the place they were collected and gobies were anaesthetised using clove oil and preserved in formaldehyde solution (4\%).

Fish were collected using electrofishing (IUP-12, Poznan, Poland and type EFGI 650, BSE Bretschneider Spezialelektornik, Germany), transported in aerated tanks to the laboratory and, after $24 \mathrm{~h}$ of acclimation, placed in 70 -L aerated aquaria equipped with grey PVC half-pipes (about $10 \mathrm{~cm}$ long and wide, used as shelters) without any substrate. To maintain proper living conditions, water in the aquaria was exchanged constantly with a flow-through system. Fish were kept at the density of 7-10 specimens per aquarium (with the number of shelters exceeding the number of fish) and fed every second day with frozen chironomid larvae. Photoperiod was set to $14 \mathrm{~h} \mathrm{L:10h} \mathrm{D} \mathrm{(day}$ 06:00-20:00) and the temperature was maintained at 18$20^{\circ} \mathrm{C}$ to reflect natural conditions. The stocking and experimental tanks were located in the same laboratory room. All actions were carried out under the permission from the Local Ethic Committee (no 12/ŁB736/2015).

Specimens of stone loaches were sampled from stony substrate. Only fish visually recognized as not ready to spawn were taken. We conducted our study in late June when psammophilous stone loaches finish their reproductive activity (Smyly, 1955; Vinyoles et al., 2010), which means they no longer stay on the sandy bottom and switch to stony habitats. At the same moment, the western tubenose goby is in the middle of its spawning period lasting from April till August (Pinchuk et al., 2003; Valová et al., 2015). Sex in stone loach was not determined as this species does not use stony shelters for spawning, but only for protection. Thus, we assumed that both males and females of the stone loach would utilize shelters similarly and would be equally affected by the presence of the western tubenose goby. Sex of tubenose goby specimens was distinguished on the basis of the shape of the urogenital papilla (Charlebois et al., 1997).

\section{Experimental setup and protocol}

The trials were carried out following the experimental setup and procedure verified in our previous studies (Grabowska et al. 2016; Błońska et al., 2016). Experiments were conducted in mildly aerated $70-\mathrm{L}$ tanks de- 
prived of substrate, with a single shelter (a half of a longitudinally cut grey PVC- pipe, the same as those used in the stocking tanks) to create a limited shelter habitat (an object of competition). The tanks were isolated from one another and from external laboratory conditions by Styrofoam curtains. A video camera (CCTV day \& night video camera, SDC425P, Samsung, South Korea) and infrared $(850 \mathrm{~nm})$ illuminator enabling observations in the darkness (MFL-I/LED5-12, Eneo, Germany) were suspended above each aquarium. During the whole experimental procedure fish were not fed and each specimen was used only once.

Experimental design aimed at verifying the influence of the tubenose goby (invasive species) on the stone loach (native species). Therefore, at the beginning of each trial a single specimen of the stone loach (hereafter named solitary stone loach as it was the only fish in the aquarium) was introduced into the experimental arena and observed for $24 \mathrm{~h}$, then intruder species (female or male tubenose goby or another stone loach) was placed in the same arena and both fish (since now the solitary stone loach changed its status and was called resident stone loach, as it was accompanied by the intruder) were observed for next $24 \mathrm{~h}$. Photoperiod was the same as in the stock tanks. Before we released the fish into the experimental aquarium (always at 10:00 a.m.), each specimen was measured with a ruler to the nearest $1 \mathrm{~mm}$ (Tab. 1). Tubenose goby individuals used were smaller than stone loach (paired Student $t$-tests performed showed significant differences; stone loach vs. tubenose goby male $t=5.76, d f=18$ $\mathrm{P}<0.001$; stone loach vs. tubenose goby female $t=16.55$, $d f=18, \mathrm{P}=<0.001$ ), which reflected the natural situation in the environment (Kováč et al., 1999; Valová et al., 2015). In conspecific stone loach pairs the resident fish did not differ in size from the intruder $(t=0.20, d f=18, \mathrm{P}=0.846)$. We ran 10 replicates for each intruder type.

We measured two parameters: time spent in the shelter by fish and aggressive behaviours displayed between the fish. From each $24 \mathrm{~h}$ period (one with a single fish and the other with two co-occurring individuals) we selected 4 hours: $2 \mathrm{~h}$ during the daylight (11:00-12:00 and 17:0018:00) and $2 \mathrm{~h}$ at night (23:00-24:00 and 04:00-05:00), in which we observed both parameters. Aggressive behaviours were divided into: i) direct aggression, when one fish bites, darts towards or jostles the other; ii) attemps to overtake the shelter, when one fish seizes the shelter or attempts to overtake it. Observations were recorded as 5min episodes. A given type of aggressive behaviour was scored, when it appeared at least once during an episode. This results in maximum 12 occurrences of a given behaviour per hour. Time spent by particular fish in the shelter was measured to the second and expressed as a percentage share of the shelter occupation time in the total observation time.

\section{Data analysis}

Shelter occupancy by fish was expressed as a proportion of $4 \mathrm{~h}$ of observation and arcsine transformed to achieve normality. To test the influence of intruder fish on stone loach we performed a three-way mixed model ANOVA with stone loach status (solitary, resident) and light conditions (day, night) as within-subject factors and intruder type (female or male tubenose goby, stone loach) as a between-subject factor. A two-way mixed model ANOVA was used to compare differences in time spent by different intruder fish in the shelter with light conditions as a within-subject factor and intruder type as a between-subject factor.

Aggression acts of the tested fish (direct aggression and attemps to overtake the shelter) were square-root transformed and compared with a three-way mixed model ANOVA with fish status (resident, intruder) and light conditions as within-subject factors and intruder type as a between-subject factor.

When necessary, significant ANOVA effects were further analysed using paired or unpaired $t$ - tests.

\section{RESULTS}

\section{Time in the shelter}

All tested species occupied the shelter mostly during the daylight. Solitary stone loach stayed in the refuge from 25 to $55 \%$ of time during the day and no more than $4 \%$ at night, which confirms its nocturnal activity (Fig. 1). After adding the intruder, time spent in the shelter by resident stone loach also depended on light conditions but its duration changed or not depending on the kind of the intruder (ANOVA, Tab. 2). In the presence of a male western tubenose goby, which occupied the shelter for almost $100 \%$ of time during the day, the resident loach decreased

Tab. 1. Mean ( \pm standard deviation) and range of the total length TL $(\mathrm{mm})$ of fish used in each treatment of the experiment.

\begin{tabular}{|c|c|c|}
\hline Pair (resident vs intruder) & Resident mean length in mm (range min-max) & Intruder mean length in $\mathrm{mm}$ (range min-max) \\
\hline Stone loach $v s$ tubenose goby male & $95.9 \pm 7.96(80-110)$ & $78.3 \pm 4.56(72-88)$ \\
\hline Stone loach $v s$ tubenose goby female & $86.8 \pm 3.66(80-92)$ & $62.5 \pm 2.46(59-66)$ \\
\hline Stone loach vs stone loach & $94.6 \pm 9.18(82-110)$ & $93.8 \pm 7.97(83-110)$ \\
\hline
\end{tabular}


its shelter occupancy from $40 \%$ (observed during its solitary period) to $4 \%$ of time (Fig. 1). After the introduction of a female western tubenose goby or a stone loach intruder, the resident loach slightly increased duration of their staying in the shelter in daylight (on average by $6 \%$ of time compared to the behaviour during the solitary period; Fig. 1), but this difference was not statistically significant (t-test, Fig. 1).

Tab. 2. Three-way mixed model ANOVA table to test the differences of light conditions (day, night) and fish status (solitary, resident) as within-subject factors and intruder species (male and female tubenose goby, stone loach) as a between-subject factor on time spent in the shelter by resident stone loach. Significant results are underlined.

\begin{tabular}{|c|c|c|c|}
\hline Effect & df & $F$ & $\mathbf{P}$ \\
\hline Fish status & 1 & 1.189 & 0.285 \\
\hline Fish status $\times$ intruder & 2 & 3.432 & $\underline{0.047}$ \\
\hline Error & 27 & & \\
\hline Light conditions & 1 & 20.712 & $\leq 0.001$ \\
\hline Light conditions $\times$ intruder & 2 & 0.244 & 0.785 \\
\hline Error & 27 & & \\
\hline Fish status $\times$ light conditions $\times$ intruder & 2 & 4.528 & $\underline{0.020}$ \\
\hline Error & 27 & & \\
\hline Intruder & 2 & 0.077 & 0.926 \\
\hline Error & 27 & & \\
\hline
\end{tabular}

df, degrees of freedom.

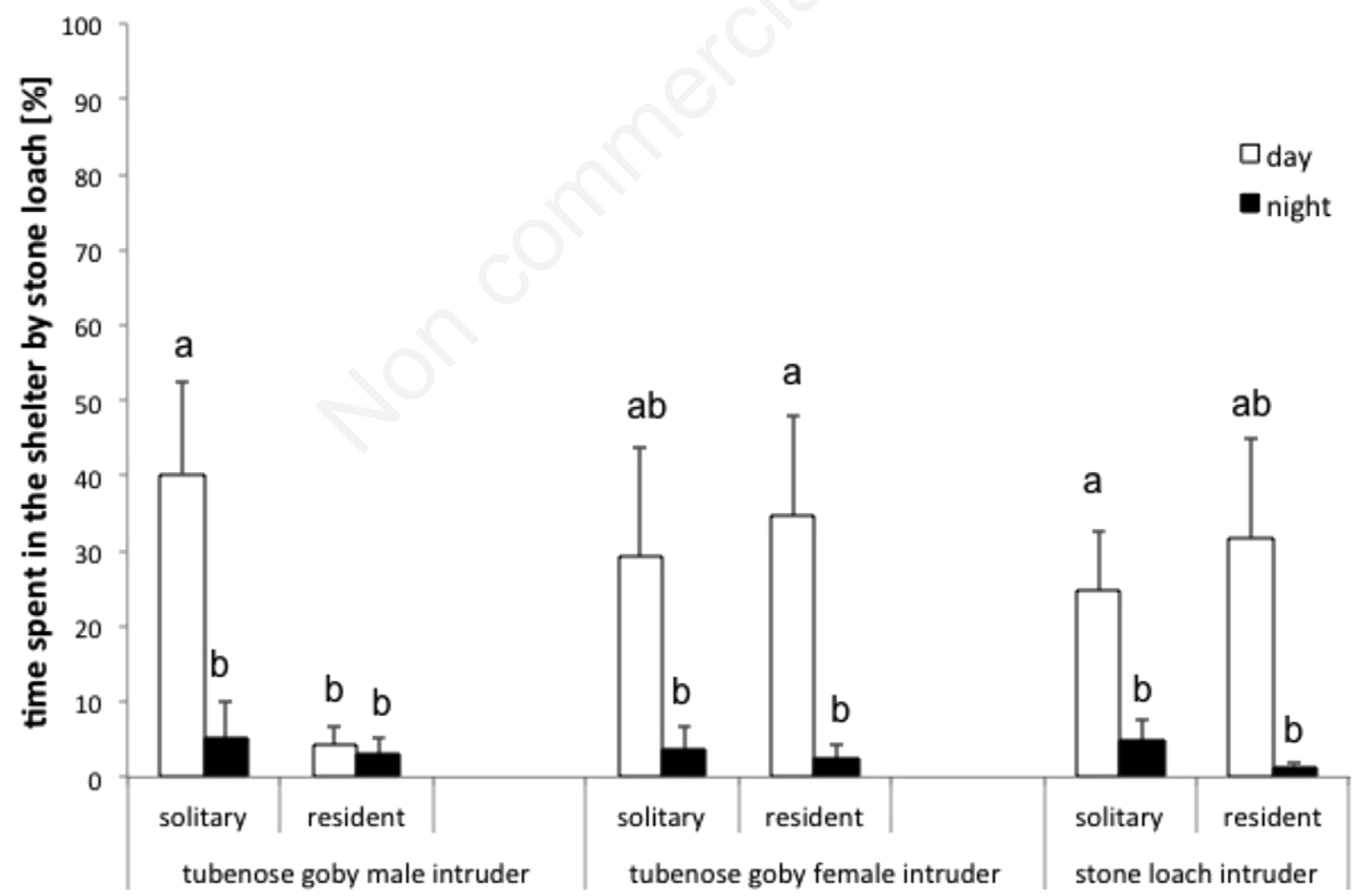

Fig. 1. Comparison of shelter occupation by stone loach (during its solitary and resident period) accompanied by different intruders (male or female western tubenose goby or another stone loach). Error bars indicate the standard errors of the mean. Treatments labelled with different letters above the bars differed significantly $(\mathrm{P}<0.05)$ from one another with respect to the fish behaviour (pairwise $t$-tests). 
Shelter occupancy by the intruding fish depended on light conditions and intruder type (ANOVA, Tab. 3). Tubenose goby occupied the refuge longer in daylight than at night independently of sex. During the day, male tubenose goby stayed in the shelter 1.5 times longer than female goby and 4 times longer than stone loach intruders (Fig. 2). At night, both male and female goby occupied the shelter significantly longer than stone loach intruders ( $t$-tests, Fig. 2).

\section{Aggression acts}

Kind of an intruding fish affected direct aggression (significant intruder effect in ANOVA, Tab. 4). Stone loach in conspecific pairs were significantly more aggressive towards each other than fish in heterospecific combinations ( $t$-tests, Fig. 3).

Attempts to overtake the shelter depended on fish status (significant fish status effect in ANOVA, Tab. 5), with residents attempting to seize the shelter more often than intruders (Fig. 3).

\section{DISCUSSION}

As demonstrated in our experiments, only male western tubenose goby influenced the time spent by stone loach in the shelter, reducing it considerably. In the presence of

Tab. 3. Two-way mixed model ANOVA table to test the differences in time spent by intruder fish in the shelter with light conditions (day, night) as a within-subject factor and intruder species (male and female tubenose goby, stone loach) as a between-subject factor. Significant results are underlined.

\begin{tabular}{|c|c|c|c|}
\hline Effect & df & $F$ & $\mathbf{P}$ \\
\hline Light conditions & 1 & 35.510 & $\leq 0.001$ \\
\hline Light conditions $\times$ intruder & 2 & 3.591 & $\underline{0.041}$ \\
\hline Error & 27 & & \\
\hline Intruder & 2 & 17.967 & $\leq 0.001$ \\
\hline Error & 27 & & \\
\hline
\end{tabular}

df, degrees of freedom.

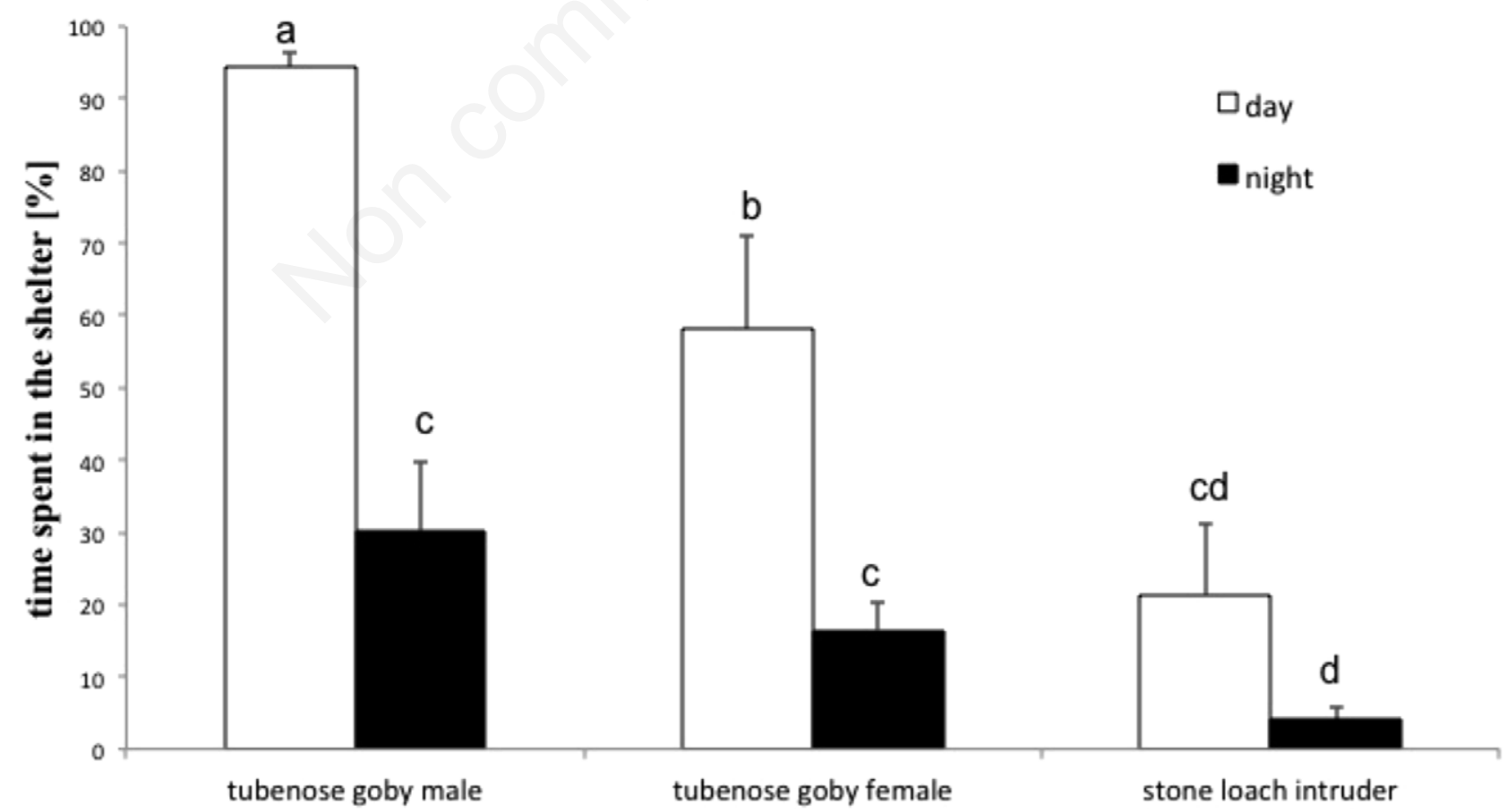

Fig. 2. Comparison of time spent in the shelter by intruding fish (male or female western tubenose goby or another stone loach). Error bars indicate the standard errors of the mean. Treatments labelled with different letters above the bars differed significantly $(\mathrm{P}<0.05)$ from one another with respect to the fish behaviour (pairwise $t$-tests). 
female goby the resident stone loach occupied the shelter as long as accompanied by a conspecific. It confirmed that male and female tubenose gobies during their reproductive period differ between each other in their influence on the stone loach. As male goby occupied the shelter for almost $100 \%$ of time during the day, stone loach did not have an opportunity to stay there. In contrast, female gobies spent less time in the shelter, though still $60 \%$ of observation time. Male gobies find a nesting place and guard the eggs, while females stay in the vicinity, entering the nest only to spawn and usually eggs of more than one female are laid in the nest. Successful reproduction depends on the success in gaining the necessary resources, which influences the partner choice (Meunier et al., 2009). Thus, shelter competition is probably much stronger in males than in females, which usually compete for a sexual partner instead. Based on our results, there is a possibility that under natural conditions male tubenose goby would force stone loach to concede from their preferred habitats, especially in late spring and early summer, when gobies are in reproductive state and stone loach have already finished their reproductive season.

The shelter occupation was not associated with aggression acts displayed by male goby, which were exhibited more frequently by stone loach intruders than by gobies. Our previous studies on the racer goby and European bullhead confirmed greater aggressiveness of gobies during spawning time compared to non-reproductive periods (Grabowska et al., 2016). Thus, we also expected considerable aggression of the western tubenose goby in our experiments. Surprisingly, in the present study aggression acts were very rare in heterospecific pairs. This may result in different value of the resource for the bullhead and stone loach. The European bullhead is strongly associated with shelters (Mills and Mann, 1983; Carter et al., 2004) and continues its attempts to overtake the resource even if the goby competitor turns out to be stronger (Kakareko et al., 2013; Grabowska et al., 2016). How-

Tab. 4. Three-way mixed model ANOVA table to test the effect of intruder species (male and female tubenose goby, stone loach) as a between-subject factor and light conditions (day, night) and fish status (resident, intruder) as within-subject factors on direct aggression behaviour displayed by fish. Significant results are underlined.

\begin{tabular}{|c|c|c|c|}
\hline Effect & df & $F$ & $\mathbf{P}$ \\
\hline Fish status & 1 & 0.137 & 0.714 \\
\hline Fish status $\times$ intruder & 2 & 1.658 & 0.209 \\
\hline Error & 27 & & \\
\hline Light conditions & 1 & 0.135 & 0.716 \\
\hline Light conditions $\times$ intruder & 2 & 0.192 & 0.827 \\
\hline Error & 27 & & \\
\hline Fish status $\times$ light conditions & 1 & 0.180 & 0.674 \\
\hline Fish status $\times$ light conditions $\times$ intruder & 2 & 1.970 & 0.159 \\
\hline Error & 27 & & \\
\hline Intruder & 2 & 10.637 & $\leq 0.001$ \\
\hline Error & 27 & & \\
\hline
\end{tabular}

df, degrees of freedom.

Tab. 5. Three-way mixed model ANOVA table to test the effect of intruder species (male and female tubenose goby, stone loach) as a between-subject factor and light conditions (day, night) and fish status (resident, intruder) as within-subject factors on attempts to overtake the shelter displayed by fish. Significant results are underlined.

\begin{tabular}{|c|c|c|c|}
\hline Effect & df & $F$ & $\mathbf{P}$ \\
\hline Fish status & 1 & 6.181 & $\underline{0.019}$ \\
\hline Fish status $\times$ intruder & 2 & 1.582 & 0.224 \\
\hline Light conditions & 1 & 0.448 & 0.509 \\
\hline Light conditions $\times$ intruder & 2 & 1.518 & 0.237 \\
\hline Error & 27 & & \\
\hline Fish status $\times$ light conditions $\times$ intruder & 2 & 0.561 & 0.577 \\
\hline Error & 27 & & \\
\hline Intruder & 2 & 0.485 & 0.621 \\
\hline Error & 27 & & \\
\hline
\end{tabular}

df, degrees of freedom. 
ever, in the case of the European bullhead losing the shelter may have more severe consequences than for the stone loach, as the former loses not only the protection against predators, but also spawning opportunity. It was already observed in the field that bullhead populations start to decrease in the presence of gobies (Jurajda et al., 2005; Van Kessel et al., 2016).

Direct aggression between stone loaches was at least ten times more intense than the one observed between stone loach and tubenose goby. Intraspecific hostility displayed more often than interspecific aggression was also observed in our previous study on interactions between European bullheads (Błońska et al., 2016). However, such a high aggression displayed by stone loach like that observed in our experiments is in contrast to the most of the studies, showing the stone loach as a social, evasive species (Prenda et al., 1997; Fischer, 2000), which does not exhibit competitive behaviour and even shares shelters with conspecifics
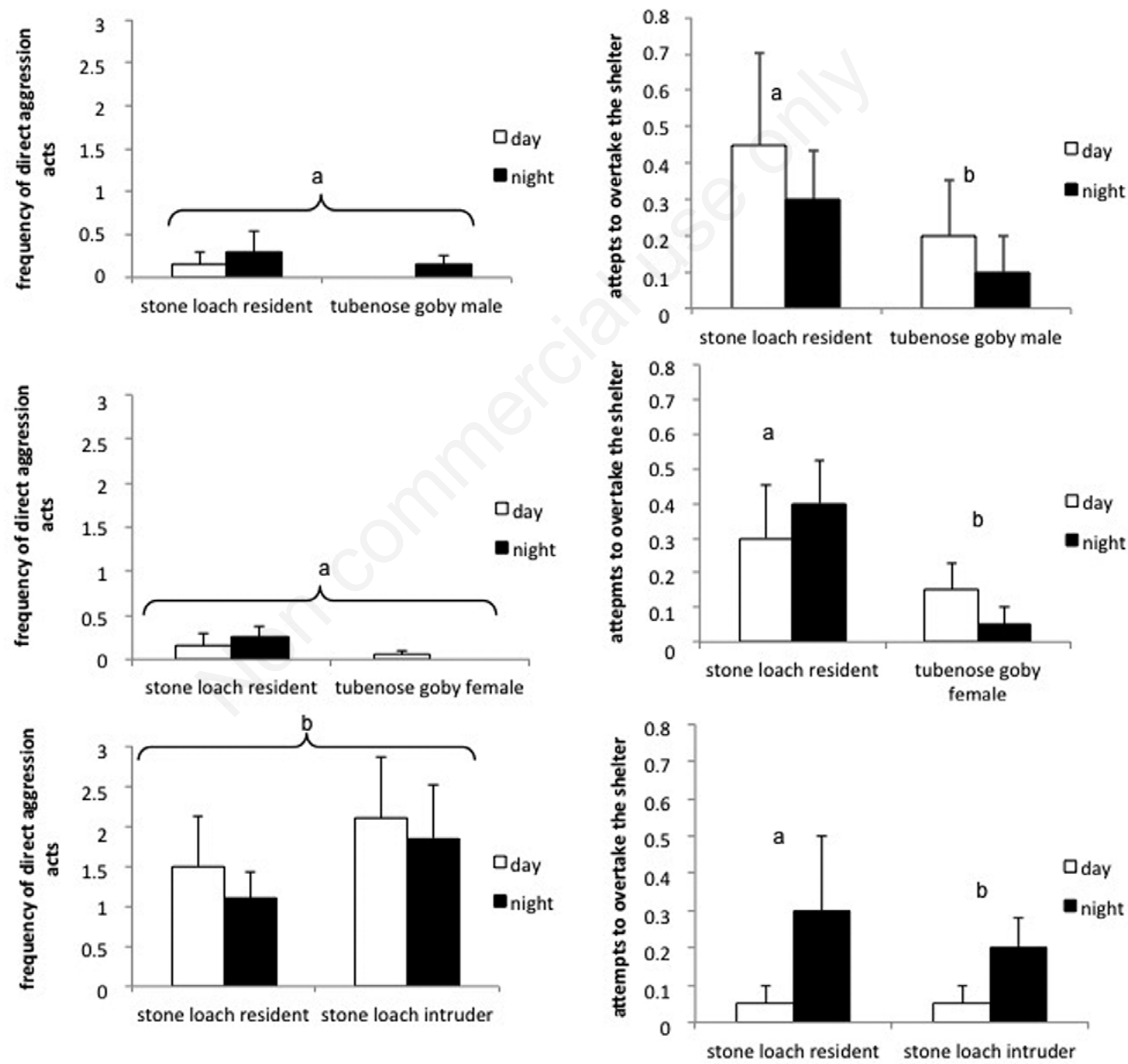

Fig. 3. Direct aggression acts and attempts to overtake the shelter displayed by resident and intruder fish expressed as the mean $( \pm \mathrm{SE})$ frequency of 5-min episodes with an occurrence of particular behaviour per 48 episodes analysed (total observation time: 4 h). Treatments labelled with different letters above the bars differed significantly $(\mathrm{P}<0.05)$ from one another with respect to the fish behaviour (pairwise $t$-tests). 
(Van Kessel et al., 2011). This may be accounted for by a different experimental design. In Prenda et al. (1997) and Van Kessel et al. (2011), fish had more than one habitat offered and were able to shift from a preferred location to a suboptimal one under competition. In our study, there was only one shelter. Thus, when the rival was present, stone loaches were forced to compete, share or abandon the limited resource. In our study, stone loach attempted to compete for the shelter with conspecific intruders resulting in increased intraspecific aggression.

The nocturnal activity of both tested species and their need to find a refuge during the day was confirmed in the present study. The reduced activity during the day, staying in the shelter, and higher nocturnal activity is a common antipredator strategy for benthic, poorly swimming, species such as the stone loach (Fischer, 2004). For the stone loach, the affinity for a shelter during the daylight was found to be so fixed behaviour that it was displayed even by starved fish and when the predator threat was not real, but only anticipated (Fischer, 2004). Thus, the shelter loss must be very stressful for this species, increasing its exposure to predation.

There are contrasting reports from field observations and some authors indicate that stone loach populations are declining in co-occurrence with Ponto-Caspian gobies (Jurajda et al., 2005). On the other hand, other studies have found no evidence for the adverse impact of gobiids (Piria et al., 2016). In the present study, we indicated the negative influence of the tubenose goby on stone loach under laboratory conditions. Nevertheless, evasive strategy and ability to live under variable conditions (Fischer, 2000) provides the stone loach with the possibility to co-exist even with aggressive species (Prenda et al., 1997; Nilsson et al., 2010). Habitat partitioning is one of the mechanisms of competition avoidance (Welton et al., 1991). Besides, the increased risk of predation may indirectly promote species co-existence at high interspecific densities (Nilsson et al., 2010).

\section{CONCLUSIONS}

In the present study, we confirmed the influence of male tubenose goby on shelter occupancy of stone loach. Although aggressive acts between the competitors were rare, the males of other Ponto-Caspian goby invaders are known of their high aggressiveness and successful seizing of resources (e.g., habitat, food, nesting sites). Thus, nonnative gobies appear to constitute a potential threat to native species with similar ecological requirements. For nocturnal species of strong shelter affinity, such as the stone loach, the loss of shelter during the daylight seems to be very stressful as it increases their exposure to predator pressure.

\section{ACKNOWLEDGMENTS}

The study was supported by an internal grant from the University of Lodz (5811/E-345/M/2015, 5811/E$345 / \mathrm{M} / 2016$ ). The authors would like to thank B. Janic and L. Marszał for their assistance in the field.

\section{REFERENCES}

Balshine S, Verma A, Chant V, Theysmeyer T, 2005. Competitive interactions between round gobies and logperch. J. Great Lakes Res. 31:68-77.

Błońska D, Kobak J, Kakareko T, Grabowska J, 2016. Can the presence of alien Ponto-Caspian gobies affect shelter use by the native European bullhead? Aquat. Ecol. 50:653-665.

Carter MG, Copp GH, Szomlai V, 2004. Seasonal abundance and microhabitat use of bullhead Cottus gobio and accompanying fish species in the River Avon (Hampshire), and implications for conservation. Aquat. Conserv. 14:395-412.

Charlebois PM, Marsden JE, Goettel RG, Wolfe RK, Jude DJ, Rudnika S, 1997. The round goby, Neogobius melanostomus (Pallas), a review of European and North American literature. Illinois-Indiana Sea Grant Program and Illinois Natural History Survey, Zion: 74 pp.

Copp GH, Bianco PG, Bogutskaya N, Erős T, Falka I, Ferreira MT, Fox MG, Freyhof J, Gozlan RE, Grabowska J, Kováč V, Moreno-Amich R, Naseka AM, Peňáz M, Povž M, Przybylski M, Robillard M, Russell IC, Stakènas S, Šumer S, Vila-Gispert A, Wiesner C, 2005. To be, or not to be, a nonnative freshwater fish? J. Appl. Ichthyol. 21:242-262.

Dubs DOL, Corkum LD, 1996. Behavioural interactions between round gobies (Neogobius melanostomus) and mottled sculpins (Cottus bairdi). J. Great Lakes Res. 22:838-844.

Fischer P, 2000. Test of competitive interactions for space between two benthic fish species, burbot Lota lota, and stone loach Barbatula barbatula. Environ. Biol. Fish. 58:439-446.

Fischer P, 2004. Nocturnal foraging in the stone loach (Barbatula barbatula): fixed or environmentally mediated behavior? J. Freshwater Ecol. 19:77-85.

Gozlan RE, Britton JR, Cowx I, Copp GH, 2010. Current knowledge on non-native freshwater fish introductions. J. Fish Biol. 76:751-786.

Grabowska J, Pietraszewski D, Ondracková M, 2008. Tubenose goby Proterorhinus marmoratus (Pallas, 1814) has joined three other Ponto-Caspian gobies in the Vistula River (Poland). Aquat. Invasions 3:250-254.

Grabowska J, Kotusz J, Witkowski A, 2010. Alien invasive fish species in Polish waters: an overview. Folia Zool. 59:73-85.

Grabowska J, Kakareko T, Błońska D, Przybylski M, Kobak J, Copp GH, 2016. Interspecific competition for a shelter between non-native racer goby and native European bullhead under experimental conditions-Effects of season, fish size and light conditions. Limnologica 56:30-38.

Janssen J, Jude DJ, 2001. Recruitment failure of mottled sculpin Cottus bairdi in Calumet Harbor, southern Lake Michigan, induced by the newly introduced round goby Neogobius melanostomus. J. Great Lakes Res. 27:319-328.

Jażdżewski M, Błońska D, Marszał L, Przybylski M, Janic B, 
Pietraszewski D, Tybulczuk S, Zieliński P, Grabowska J, Zięba G, 2012. [Monitoring of fish fauna in the Skrwa Prawa River System: continuation in the 2010 and 2011].[Article in Polish]. Sci. Ann. Pol. Angl. Ass. 25: 5-29.

Jermacz Ł, Kobak J, Dzierżyńska A, Kakareko T, 2015. The effect of flow on the competition between the alien racer goby and native European bullhead. Ecol. Freshwater Fish 24:467-477.

Jurajda P, Černý J, Polačik M, Valová Z, Janác M, Blažek R, Ondračková M, 2005. The recent distribution and abundance of non-native Neogobius fishes in the Slovak section of the River Danube. J. Appl. Ichthyol. 21:319-323.

Kakareko T, Kobak J, Grabowska J, Jermacz Ł, Przybylski M, Poznańska M, Pietraszewski D, Copp GH, 2013. Competitive interactions for food resources between invasive racer goby Babka gymnotrachelus and native European bullhead Cottus gobio. Biol. Invasions 15:6519-6533.

Keller RP, Geist J, Jeschke JM, Kühn I, 2011. Invasive species in Europe: ecology, status, and policy. Env. Sci. Eur. 23:1.

Kováč V, Copp GH, Francis MP, 1999. Morphometry of the stone loach, Barbatula barbatula: do mensural characters reflect the species' life history thresholds? Environ. Biol. Fish. 56:105-115.

MacKenzie AR, Greenberg L, 1998. The influence of instream cover and predation risk on microhabitat selection of stone loach Barbatula barbatula (L.). Ecol. Freshwater Fish 7:87-94.

Meunier B, Yavno S, Ahmed S, Corkum LD, 2009. First documentation of spawning and nest guarding in the laboratory by the invasive fish, the round goby (Neogobius melanostomus). J. Great Lakes Res. 35:608-612.

Miller PJ, 1984. The tokology of gobioid fishes, p. 119-153. In: G.W. Potts and R.J. Wootton (eds.), Fish reproduction: strategies and tactics. Tactics Academic Press, London.

Mills CA, Mann RHK, 1983. The bullhead Cottus gobio, a versatile and successful fish, p. 76-88. In: Fifty-first annual report for the year ended 31st March 1983, Ambleside, UK, Freshwater Biological Association.

Nilsson E, Persson A, Nilsson PA, 2010. Interspecific competition and predation: relative effects on foragers and their densities. Behav. Ecol. Sociobiol. 64:729-736.

Penczak T, Kruk A, Galicka W, Tybulczuk S, Marszał L, Pietraszewski D, Tszydel M, 2010. [Fish fauna of the Bug River].[Article in Polish]. Sci. Ann. Pol. Angl. Assoc. 23:5-24.

Pinchuk V, Vasil'eva ED, Vasil'ev VP, Miller PJ, 2003. Proterorhinus marmoratus (Pallas, 1814), p. 72-93. In: P. Miller (ed.), The freshwater fishes of Europe. Mugilidae,
Atherinidae, Atherionopsidae, Blennidae, Odontobutidae, Gobiidae. AULA-Verlag.

Piria M, Jakšić G, Jakovlić I, Treer T, 2016. Dietary habits of invasive Ponto-Caspian gobies in the Croatian part of the Danube River basin and their potential impact on benthic fish communities. Sci. Total Environ. 540:386-395.

Prenda MJ, Rossomanno S, Armitage PD, 1997. Species interactions and substrate preferences in three small benthic fishes. Limnetica 13:47-53.

Rahel FJ, 2002. Homogenization of freshwater faunas. Ann. Rev. Ecol. Syst. 33:291-315.

Ricciardi A, 2001. Facilitative interactions among aquatic invaders: is an "invasional meltdown" occurring in the Great Lakes? Can. J. Fish Aquat. Sci. 58:2513-2525.

Ricciardi A, MacIsaac HJ, 2000. Recent mass invasion of the North American Great Lakes by Ponto-Caspian species. Trends Ecol. Evol. 15:62-65.

Roche KF, Janač M, Jurajda P, 2013. A review of Gobiid expansion along the Danube-Rhine corridor - geographical change as a driver for invasion. Knowl. Manag. Aquat. Ecosyst. 411:01.

Semenchenko V, Grabowska J, Grabowski M, Rizevsky V, Pluta M, 2011. Non-native fish in Belarusian and Polish areas of the European central invasion corridor. Oceanol. Hydrobiol. Stud. 40:57-67.

Smyly WJP, 1955. On the biology of the stone loach Nemacheilus barbatula (L.). J. Anim. Ecol. 24:167-186.

Valová Z, Konečná M, Janáč M, Jurajda P, 2015. Population and reproductive characteristics of a non-native western tubenose goby (Proterorhinus semilunaris) population unaffected by gobiid competitors. Aquat. Invasions 10:57-68.

Van Kessel N, Dorenbosch M, De Boer MRM, Leuven RSEW, Van der Velde G, 2011. Competition for shelter between four invasive gobiids and two native benthic fish species. Curr. Zool. 57:844-851.

Van Kessel N, Dorenbosch M, Kranenbarg J, van der Velde G, Leuven RSEW, 2016. Invasive Ponto-Caspian gobies rapidly reduce the abundance of protected native bullhead. Aquat. Invasions 11:179-188.

Villéger S, Blanchet S, Beauchard O, Oberdorff T, Brosse S, 2011. Homogenization patterns of the world's freshwater fish faunas. P. Natl. Acad. Sci. USA 108:18003-18008.

Vinyoles D, De Sostoa A, Franch C, Maceda-Veiga A, Casals F, Caiola N, 2010. Life-history traits of the stone loach Barbatula barbatula. J. Fish Biol. 77:20-32.

Welton JS, Mill CA, Pygott JR, 1991. The effect of interaction between the stone loach Noemacheilus barbatulus (L.) and the bullhead Cottus gobio (L.) on prey and habitat selection. Hydrobiologia 220:1-7. 